\title{
Memorization or understanding: Are we teaching the right thing?
}

\section{Eric Mazur}

Eric Mazur, "Memorization or understanding: Are we teaching the right thing?," Proc. SPIE 9663, Eighth International Topical Meeting on Education and Training in Optics and Photonics, 96631N (6 October 2003); doi: 10.1117/12.2208470

SPIE Event: Eighth International Topical Meeting on Education and Training in Optics and Photonics, 2003, Tucson, Arizona, United States 


\title{
Memorization or understanding: Are we teaching the right thing?
}

\author{
Eric Mazur, Harvard Univ., Cambridge, MA, USA. \\ mazur@physics.harvard.edu
}

\begin{abstract}
By shifting the focus in lectures from delivering information to helping students synthesize information remarkable improvements in understanding can be achieved. The method to accomplish this improvement, Peer Instruction, is easily adapted and implemented.
\end{abstract}

Summary: Education is more than just transfer of information, yet that is what is mostly done in large introductory courses -- instructors present material (even though this material might be readily available in printed form) and for students the main purpose of lectures is to take down as many notes as they can. Few students have the ability, motivation, and discipline to synthesize all the information delivered to them. Yet synthesis is perhaps the most important -- and most elusive -- aspect of education. Students get frustrated because they are unable to grasp simple concepts. Instructors get frustrated because they don't know how to help their students grasp the material.

The problem has a relatively simple solution: shift the focus in lectures from delivering information to synthesizing information. This requires students to take more responsibility for obtaining the information in the first place, but this is a process that they are quite good at anyway. With examples from my own discipline (physics), I will illustrate how I discovered rampant problems in my own lectures and how I have begun to remedy the problem. 